\title{
DAMPAK PENAMBANGAN EMAS TERHADAP LINGKUNGAN DI DESA TAMILOUW KECAMATAN AMAHAI, KABUPATEN MALUKU TENGAH
}

\author{
IMPACT OF GOLD MINING ON THE ENVIRONMENT IN TAMILOUW VILLAGE, AMAHAI \\ DISTRICT, CENTRAL MALUKU REGENCY
}

\author{
Oleh \\ Debby V Pattimahu ${ }^{1)}$, Antho Netty Siahaya ${ }^{2)}$, Terezia V Pattimahu ${ }^{3)}$ \\ ${ }^{1)}$ Jurusan Kehutanan Fakultas Pertanian;Unpatti \\ ${ }^{2)}$ Jurusan Kimia Fakultas MIPA, Unpatti; \\ ${ }^{3)}$ Jurusan Studi PembangunanFakultas Ekonomi dan Bisnis, Unpatti. \\ Jl Ir. M Putuhena ,Kampus Poka Ambon, 97233 \\ Email : debbypattimahu@ gmail.com
}

\begin{abstract}
Abstrak
Pengelolaan sumberdaya alam yang tidak memperhatikan kaidah-kaidah konservasi sumberdaya alam dan lingkungan akan berimplikasi negatif bagi keberlanjutan lingkungan. Dengan adanya penemuan emas di pantai Desa Tamiouw saat ini, membuat aktifitas warga beralih pada kegiatan penambangan emas di wilayah pesisir pantai Tamilouw. Penelitian ini bertujuan untuk mengetahui dampak penambangan emas terhadap lingkungan fisik di Desa Tamilouw Kecamatan Amahai Kabupaten Maluku Tengah, disamping itu juga untuk mengetahui dampak penambangan emas terhadap lingkungan sosial dan ekonomi masyarakat setempat. Penelitian dilakukan dengan menggunakan metode non experimental yaitu deskriptif eksploratif, pengamatan lapangan (observasi) dan studi literatur pustaka. Hasil penelitian menunjukkan bahwa penambangan emas yang dilakukan di Desa Tamilouw menggunakan merkuri pada proses pemisahan emas dengan pasir, walaupun ada juga sebagian masyarakat yang melakukan pengolahan secara tradisional. Hal yang dikuatirkan sebagian masyarakat, yakni adanya pembuangan limbah merkuri tidak dilakukan sesuai prosedur yang disyaratkan, sehingga nantinya berdampak pada kerusakan lingkungan. Adanya aktifitas penambangan tidak berpengaruh terhadap aspek sosial yakni pendidikan, kesehatan serta umur dan jenis kelamin; sedangkan dari aspek ekonomi, turut berkontribusi dalam peningkatan pendapatan masyarakat.
\end{abstract}

Kata kunci : Penambangan emas, lingkungan, Desa Tamilouw

\begin{abstract}
Natural resource management that does not pay attention to the principles of conservation of natural resources and the environment will have negative implications for environmental sustainability. With the discovery of gold on the coast of Tamiouw Village at this time, residents' activities have shifted to gold mining activities in the coastal area of Tamilouw. This study aims to determine the impact of gold mining on the physical environment in Tamilouw Village, Amahai District, Central Maluku Regency, as well as to determine the impact of gold mining on the social and economic environment of the local community. The research was conducted using non-experimental methods, namely exploratory descriptive, field observations and literature study. The results showed that gold mining carried out in Tamilouw Village uses mercury in the process of separating gold from sand, although there are also some people who carryout traditional processing. What some people are worried about is that the disposal of mercury waste is not carried out according to the required procedures, so that it will have an impact on environmental damage. The existence of mining activities does not affect the social aspects, namely education, health and age and gender; while from the economic aspect, it also contributes to increasing people's income. Keywords : Gold mining, environment, Tamilouw Villageout traditional processing. What some people are worried about is that the disposal of mercury waste is not carried out according to the required procedures, so that it will have an impact on environmental damage. The existence of mining activities does not affect the social aspects, namely education, health and age and gender; while from the economic aspect, it also contributes to increasing people's income.
\end{abstract}

Keywords : Gold mining, environment, Tamilouw Village

DOI:10.30598/jhppk.2021.5.1.90

ISSN ONLINE:2621-8798

Page 90 


\section{PENDAHULUAN}

Salah satu tujuan pembangunan dari Indonesia adalah pembangunan berkelanjutan yang berarti tercipta keseimbangan antara ekonomi serta lingkungan. Hal ini juga berarti bahwa eksploitasi sumber daya secara berlebihan atau pembangunan dengan dampak negatif mulai dikurangi. Kerusakan lingkungan dapat terjadi akibat adanya tindakan yang menimbulkan perubahan langsung ataupun Sumberdaya alam secara umum terbagi atas sumberdaya alam yang dapat diperbaharui dan dan sumberdaya alam yang tidak dapat diperbaharui. Dari sudut pemakaian sumberdaya alam

Bahan galian pertambangan diatur di dalam Undang-Undang No 4 Tahun 2009 tentang ketentuan pokok pertambangan. Dalam UU no 4 Tahun 2009 ini penggolongan bahan galian lebih menitikberatkan pada aspek teknis, yaitu berdasarkan pada kelompok atau jenis bahan galian, yaitu dalam empat golongan, yaitu : pertambangan mineral radio aktif; pertambangan

Desa Tamilouw adalah salah satu desa yang terdapat di Kecamatan Amahai, Kabupaten Maluku tengah. Dengan adanya penemuan emas di pantai Desa Tamiouw saat ini, membuat aktifitas warga beralih pada kegiatan penambangan emas di wilayah pesisir pantai Tamilouw. Masyarakat setempat mulai bekerja melakukan kegiatan penambangan untuk tidak langsung sifat fisik atau hayati sehingga lingkungan hidup tidak berfungsi lagi dalam menunjang pembangunan berkelanjutan (KMNLH,1998). Selain bencana yang secara kasat mata alamiah, juga bisa membuat bencanabencana alam yang mengakibatkan bencana sosial. Adanya berbagai aktifitas yang dilakukan masyarakat seperti : perambahan hutan, pencurian ikan, dan penambangan liar, adalah beberapa fakta pemanfaatan sumberdaya yang tidak ramah lingkungan.

yang tidak dapat diperbaharui harus dikelola secara bijaksana agar dapat dipertahankan keberlanjutannya. Hasil yang diperoleh dari pemanfaatan sumberdaya alam harus dikelola menurut kaidah-kaidah kelestarian sumberdaya alam (Salim 2007).

mineral logam; pertambangan mineral bukan logam, pertambangan bahan-bahan galian tersebut diatas dalam perundang-undang agar tetap memperhatikan kelestarian fungsi lingkungan. Pengaturan, pelaksanaan dan pengawasan bahanbahan galian ini melibatkan pemerintah, pengusaha dan masyarakat.

kepentingan hidup sehari-hari. Kenyataan yang terlihat saat ini adalah masyarakat Desa Tamilouw yang melakukan kegiatan penambangan di pesisir pantai tidak memikirkan dampak penambangan tersebut terhadap lingkungan sekitarnya. Penelitian ini bertujuan untuk mengetahui dampak penambangan emas terhadap lingkungan fisik di Desa Tamilouw Kecamatan Amahai Kabupaten 
Maluku Tengah, disamping itu juga untuk mengetahui dampak penambangan emas terhadap

\section{METODE PENELITIAN}

Penelitian dilaksanakan di Desa

Tamilouw Kecamatan Amahai Maluku

Tengah. Penelitian berlangsung April 2021.

Penelitian dilakukan dengan menggunakan metode non experimental yaitu deskriptif eksploratif, pengamatan lapangan (observasi) dan studi literatur pustaka guna mengumpulkan data yang diperlukan. Jenis data yang digunakan meliputi data primer dan data sekunder.

Pengambilan sampel responden masyarakat dilakukan dengan purposive sampling, yaitu anggota masyarakat yang tinggal di desa dan memiliki akses aktitifitas penambangan dan merupakan kepala keluarga. Pengambilan secara purposive ini diartikan sebagai pengambilan responden dengan keadaan yang dikehendaki (Nazir, 1983). Untuk wawancara dilakukan pada pihak-pihak yang berkompeten dan memiliki pengetahuan yang

\section{HASIL DAN PEMBAHASAN}

\section{Proses Penambangan Emas di Desa Tamilouw Kecamatan Amahai}

Proses penambangan yang terdapat di Desa Tamilouw dilakukan dengan menggunakan peralatan sederhana dan seadanya. Dengan peralatan yang akan dipergunakan sudah disiapkan sebelum memulai aktivitas penambangan. Setiap penambang selalu sabar dalam melakukan lingkungan sosial dan ekonomi masyarakat setempat.

baik. Sebanyak 30 responden yang dipilih adalah masyarakat yang tinggal di lokasi penelitian.

Wawancara dilakukan dengan menggunakan metode kuisioner, dengan sasaran utamanya adalah masyaraka. Wawancara merupakan salah cara untuk mengumpulkan data pokok di lapangan, yang bertujuan untuk memperoleh informasi mengenai kawasan penelitian. Data sosial ekonomi dan budaya masyarakat setempat dilakukan dilakukan dengan wawancara dan penyebaran kuesioner.

Metode analisis data adalah metode analisis deskriptif. Data yang diperoleh dikumpulkan, diolah dengan cara tabulasi data dan kemudian dianalisis sesuai jenis data dan tujuan penelitian. Analisis data yang digunakan adalah analisis deskriptif yang dikualifikasika $n$ sesuai kondisi real di lokasi penelitian.

pekerjaannya yang setiap hari harus berendam di dalam air dan bekerja keras untuk memenuhi kebutuhan keluarga para penambang. Aktifitas penambangan dilakukan dari pagi sampai sore hari, sedangkan proses pengolahan emas dilakukan di rumah masyarakat sendiri.

Berdasarkan hasil pengamatan atau observasi yang dilakukan dilapangan memperlihatkan yang lebih banyak beraktifitas di lokasi pertambangan adalah ibu-ibu rumah tangga dan anak-anak usia sekolah. Hal ini 
sesuai dengan pendapat beberapa pakar (Rosalda,1974; cutenr,1974; Mac Comrmac 1980 seperti dikutip dalam Irwan Abdulah 2003 yang

Dampak Penambangan Emas Terhadap Aspek Lingkungan.

Penambangan emas ilegal umumnya menggunakan merkuri pada proses pengolahan emas, dimana jika tidak dikelola dengan baik akan mencemari lingkungan. hal ini sesuai dengan pendapat (Yustiawati., et al., 2003) yang menyatakan bahwa penambangan emas tradisional sering dianggap sebagai penyebab kerusakan dan pencemaran lingkungan, karena para penambang menggunakan merkuri untuk mengekstrak emasnya. Data hasil observasi dan wawancara yang dilakukan menemukan fakta bahwa di Desa Tamilouw untuk memisahkan emas dan pasir yangtercampur, walaupun ada juga sebagian masyarakat yang melakukan pengolahan secara tradisional. Menurut sebagian warga, pengolahan emas dilakukan dengan menggunakan air raksa (merkuri). Merkuri

Hal tersebut selain tidak memaksimalkan hasil tambang juga merusak lingkungan akibat pengolahan yang konvensional dan sistem pengolahan limbah buangan yang tidak memadai. Dampak lanjutan yang diakibatkan adalah emisi merkuri terkonsentrasi pada lingkungandalam jumlah besar dan mencemari sumber air dan tanah dan selanjutnya masuk ke sungai dan bermuara di laut selanjutnya melalui jalur rantai makanan, apabila ikan-ikan yang menyatakan bahwa perempuan secara sosial akan lebih dekat dengan alam (nature) dan lakilaki dengan budaya (culture).

tergolong logam berat yang berpotensi sebagai limbah B3 (Bahan Berbahaya dan Beracun) apabila dilepas ke lingkungan. Merkuri ( $\mathrm{Hg})$ juga termasuk kontaminan Logam berat yang unik karena tidak dapat terdegradasi baik secara biologi maupun kimiawi di lingkungan. Kemungkinan yang terjadi adalah $\mathrm{Hg}$ akan mengalami transformasi sehingga dapat meningkatkan mobilitas dan sifat racunnya (Ridel Suruh et,al, 2012) Hal yang dikuatirkan sebagian masyarakat, karena adanya pembuangan limbah merkuri yang tidak dilakukan sesuai prosedur yang disyaratkan. Belum adanya legalitas dari badan terkait, maka penambangan yang dilakukan oleh masyarakat saat menjadi tidak terkoordinir dan sistem pengolahannya dilakukan secara konvensional.

berada di laut sekitar terkontaminasi merkuriakan berbahaya kepada manusia. Hal ini sesuai pendapat Marsden and Rainbow (2004) dalam A. tritugaswati et,al (1997) yang menyatakan bahwa tingginya kandungan $\mathrm{Hg}$ pada komoditi perikanan disebabkan oleh lingkungan perairan yang telah tercemar oleh limbah dimana $\mathrm{Hg}$ akan terdistribusi di berbagai komponen ekosistem laut dan kemudian terakumulasi oleh organisme, selanjutnya dikonsumsi oleh 
manusia, maka dapat membahayakan kesehatan dan bahkan menyebabkan kematian.

Disamping itu penambangan ilegal yang tidak dilakukan sesuai standar perlindungan lingkungan dapat merusak vegetasi tanah dan profil genetik tanah yang ada, sehingga tanah yang awalnya subur dapat berubah kering dan

\section{Dampak Penambangan Emas Terhadap Aspek Sosial dan Ekonomi Masyarakat}

Berdasarkan kajian aspek sosial pada aktivitas pertambangan yang terdiri dari:

\section{Penddikan}

Pada umumnya aktifitas pertambangan emas tidak mempengaruhi tingkat pendidikan

Kesehatan

Adanya pertambangan tidak berpengaruh terhadap kesehatan masyarakat untuk saat ini. Masyarakat hanya masih Umur dan Jenis Kelamin

Aktifitas penambangan emas yang dilakukan oleh masyarakat di pesisir pantai Pohon batu Desa Tamilouw umumnya melibatkan ibu-ibu rumah tangga dan anakanak usia sekolah. Hal ini sesuai dengan pendapat beberapa pakar (Rosalda,1974;

\section{Mata Pencaharian}

Umumnya masyarakat mulai beralih mata pencahariannya sebagai penambang walaupun mayoritas pekerjaannya ialah bertani. Hasil wawancara menunjukkan bahwa sebagian warga

\section{Pendapatan dan Kesempatan Kerja}

Pendapatan masyarakat yang diperoleh dari hasil bekerja sebagai penambang bila tandus. Penggalian wilayah pesisir yang tidak sesuai juga dapat mempengaruhi topogafi umum kawasan pesisir secara permanen yang dapat berakibat longsor pada badan jalan ataupun kerusakan jalan atau jalan terputus pada saat musim penghujan.

Pada masyarakat di Desa Tamilouw Kecamatan Amahai, karena dalam kondisi mewabahnya pandemic Covid 19, kegiatan pendidikan juga masih dilakukan secara online.

mengeluhkan pelayanan kesehatan karena fasilitas dan tenaga medis yang ada di desa masih sangat minim.

Cutenr,1974; Mac Comrmac 1980 seperti dikutip dalam Irwan Abdulah 2003 yang menyatakan bahwa perempuan secara sosial akan lebih dekat dengan alam (nature) dan lakilaki dengan budaya (culture). Berdasarkan aspek ekonomi yang terdiri dari: $\mid$

menyatakan bahwa aktifitas penambangan yang dilakukan setiap hari memberikan nilai pendapatan yang lebih berarti dibandingkan dengan aktifitas bertani.

dikumpulkan dalam satu sampai tiga minggu sudah cukup menambah pendapatan masyarakat dan dapat memenuhi kebutuhan sehari-hari. 
Adanya kesempatan kerja sebagai penambang memberikan dampak positif terhadap perekonomian masyarakat di Desa Tamilouw. Walaupun pengusahaan penambangan emas oleh masyarakat saat ini secara ekonomi belum menunjukan hasil yang cukup berarti bagi

Secara umum penambangan emas ini juga turut berkontribusi dalam meningkatkan perekonomian masyarakat dan dapat mengurangi masalah pengangguran. Walaupun dari sisi lain, apabila

Dengan demikian berbagai kebijakan pemerintah terhadap aktifitas pertambangan harus ditingkatkan melalui kegiatan sosialisasi dan edukasi kepada masyarakat, pembinaan dan pengawasan oleh dinas terkait. Pemerintah

Daerah harus memilki peranan dalam mengubah mata pencaharian masyarakat agar beralih profesi ke pekerjaan lain. Pemerintah juga hendaknya dapat memberikan sanksi yang

\section{KESIMPULAN}

Adanya dampak positif maupun negatif dari aktifitas penambangan yang tidak ramah lingkungan, sehingga akan berkontribusi pada kerusakan ekosistem secara umum dan mengancam kesehatan masyarakat. Oleh karena itu pemerintah kabupaten diharapkan dapat peningkatan kesejahteraannya. Beberapa kendala yang menjadi hambatan yang dirasakan masyarakat adalah keterbatasan teknologi yang digunakan, kurangnya pengetahuan mengenai potensi dan prospek pengembangannya serta terbatasnya ketersediaan data dan informasi.

penambang tidak diarahkan dengan baik dalam melakukan aktifitas penambangan ini akan merusak lingkungan secara umum dan mengakibatkan gangguan kesehatan masyarakat. tegas jika terbukti melakukan pertambangan dengan penggunaan merkuri. Upaya membangun pengetahuan, pemahaman dan kesadaran akan pentingnya lingkungan harus ditanamkan di masyarakat, melalui berbagai kegiatan penguatan kapasitas, khususnya dengan giat program penyuluhan secara terintegrasi dengan pelibatan semua pihak yang berkepentingan dalam pengelolaan lingkungan.

meningkatkan perannya dalammemberikan arahan dan penyuluhan terpadu kepada masyarakat di Desa Tamilouw, terkait dengan upaya meningkatkan pengetahuan dan pemahaman masyarakat dalam kegiatan penambangan emas.

\section{DAFTAR PUSTAKA}

Abdulah. 2003. Penelitian berwawasan Gender dalam ilmu social. Humaniora Vol. 15 Hal 225.

Astuti, W.F. 2017. Dampak Aktivitas Pertambangan Emas Tanpa Izin 
Terhadap Kesejahteraan Rumah Tangga Gurandil. Jurnal SKPM Vol.1 No.3: Institut Pertanian Bogor.

Arikunto, Suharsimi. A. 2005. Manajeman Penelitian. Jakarta: Rineka Cipta.

Hadi.2009. Pengembangan Emas Latakan Oleh Masyarakat Bombana dan Pengaruhnya Terhadap Lingkungan.(Online).(http://jurnal/pena mbangan emas.

Irwan Abdulah. 2003. Penelitian berwawasan Gender dalam ilmu social. Humaniora Vol. 15 Hal 225

Koentjraningrat. 1984.Metode-Metode Penelitian Masyarakat. jakarta: Widyadara Kumpulan Peraturan Pemerintah Pengembangan Nomor 4 Tahun $2010 \quad$ tentang Pertambangan.Yogyakarta : Pustaka Yustisia.

Nurhayati. D dan Didha Andini Putri 2019. Bioakumulasi Logam Berat Pada Kerang Hijau (Perna Viridis) Di Perairan Cirebon Beradasarkan Musim Yang Berbeda . Jurnal Akuatika Indonesia Vol. 4 No. 1 ISSN 2528-052X ; eISSN 2621-7252

Salim HS. 2006. Hukum Pertambangan di Indonesia. Jakarta: PT. Raja Grafindo Persada

Sugiyono. 2008.Metode Penelitian Kuantitatif, Kualitatif dan R\&D. Bandung: Alfabeta

Suprananto, Kusaeri. 2012. Sintong, M. 2011. Pemanfaatan Lahan Bekas Tambang Untuk Tempat Rekreasi dengan Reklamasi di Sungai Bingai Kecamatan Binjai Selatan Kodya Binjai. JURNAL GEOGRAFI, 3(2), 11-18. Soermarwoto,O. 2005. Ekologi Lingkungan Hidup dan Pembangunan. jakarta.

Subandari.2008. Kajian Pencemaran Merkuri (Hg) Terhadap air sungai menyuke Dan Gangguan kesehatan Pada Penambangan Sebagai Akibat
PenambangEmasan tanpa izin (Peti) di kecamatan Menyuke Kabupaten landak Kalimantan Barat.(http://Journal tambang emas rakyat).

Sudrajat,N. 2010. Teori dan Praktek Pertambangan Indonesia Menurut Hukum. Yogyakarta:Pustaka Yustisi.

Sugiyono. 2008. Metode Penelitian Kuantitatif, Kualitatif dan R\&D. Bandung: Alfabeta

Suprananto, Kusaeri. 2012.Tri-Tugaswati. A, Athena F.B., Agustina Lubis. Studi Pencemaran Merkuri Dan

Dampaknya Terhadap Kesehatan Masyarakat Dl Daerah Mundu Kabupaten Indramayu Buletin Penelitian Kesehatan .25 (2) 1997. 